\title{
Crimen organizado: orden divergente y vecindarios urbanos vulnerables
}

César Alfonso Velásquez Monroy. Centro de Investigaciones

Criminológicas, Policía Metropolitana de Bogotá.

RESUMEN | En la criminología el crimen organizado es asociado a actividades ilícitas planificadas y a estructuras complejas de organización. En la economía del crimen el atributo distintivo es la oferta de protección y justicia alterna al Estado. Así, el crimen organizado ingresaría a los vecindarios urbanos según modos de interacción social entre sus habitantes y su distribución por la ciudad sería desigual. Mediante información cuantitativa-descriptiva y cartográfica se identificaron vecindarios con expresiones del crimen organizado (homicidios y hurtos a residencia) en Bogotá. Observaciones de campo y entrevistas a profundidad revelaron tres tipos de vecindario que condicionan la presencia del crimen organizado. En el periférico, el control violento sobre la población juvenil es la antesala para regular la vida cotidiana de sus habitantes. En el vecindario en transición, los mercados ilegales y sus formas de regulación se posicionan junto con actividades comerciales que conectan a Bogotá con Colombia. En el conjunto cerrado, la seguridad privada debilita las relaciones de vecindario y facilita la infiltración del crimen organizado.

PALABRAS CLAVE | Violencia, transformaciones socioterritoriales, estructura urbana.

ABSTRACT | In criminology, organized crime is associated with the planning of illegal activities and complexstructures of organizations. In the economy of crime, the distinctive attribute is the offer of protection and an alternate justice to that of government or state. In effect, organized crime will enter into urban neighborhoods using different kinds of social interaction among inhabitants and with unequal distribution through the whole city. The neighborhoods with examples of organized crime (homicides and burglaries) in Bogota were identified using quantitative and descriptive information, as well as cartographic resources. Field observation's as well as in depth interviews have revealed three types of neighborhood which exhibit favorable conditions for the presence of organized crime. The remote area: the violent control of the youthfulpopulation is the precursor to the regulation of the inhabitants' daily lives. Neighborhoods in transition: illegal markets and their forms of regulation are positioned along with commercial activities, which connect Bogota with the rest of Colombia. The gated community: The interrelations of neighbor and neighborhood are weakened because of private security; which facilitates the infiltration of organized crime.

KEY WORDS | Violence, socio-territorial transformations, urban structure. 


\section{Introducción}

En Colombia el crimen organizado suele ser asociado con carteles de la droga o con grupos armados ilegales, debido al grado de planificación de sus actividades y al monopolio que detentan sobre un mercado ilegal determinado. Desde el análisis económico se ha sugerido que el crimen es organizado si ofrece servicios de protección y de justicia a uno o varios mercados ilegales específicos. La oferta de este tipo de servicios puede servir, incluso, para constituir un sistema de regulación propio dentro del mundo del hampa. ¿Tiene cabida un crimen organizado de esta manera en Bogotá, considerado el principal centro urbano del país? Para responder a esta pregunta, habría que explorar si los vecindarios urbanos bogotanos reúnen condiciones que facilitan la operación de bandas y redes delincuenciales que efectúan alguna forma de regulación sobre actividades ilegales o se apoyan en ella. Si hay evidencia al respecto, también cabe preguntar acerca del alcance social de estas regulaciones ilegales y el papel que juegan frente al orden institucional imperante.

\section{Crimen organizado: una noción en discusión}

¿Es el crimen organizado un mal o un bien? La pregunta puede sonar absurda si asumimos que todo lo ilegal es, por definición, un mal. Para los economistas, lo malo serían las costosas imperfecciones (externalidades negativas y asimetrías de información) de los mercados asociados al crimen organizado. Ejemplos de externalidades negativas, en el mercado de estupefacientes, son los delitos que cometen los adictos a estas sustancias para financiar su consumo y la atención médica que reciben de entidades públicas o caritativas, pues ellos no tienen dinero para costear un tratamiento médico. Por otro lado, los demandantes de órganos, con bajos ingresos, poseen información asimétrica con respecto a los oferentes, pues no pueden verificar la calidad de lo que pretenden comprar, bajo situaciones apremiantes de vida o muerte (Rose-Ackerman, 1985; citada en Fiorentini, 2000, pp. 446-447). De ahí que los economistas aboguen por mantener la condición de ilegalidad de los mercados en los que suele operar el crimen organizado.

No obstante, hay argumentos a favor de la legalización. El crimen organizado puede sustituir al Estado en la protección de los supuestos derechos de propiedad que se transarían en un mercado ilegal, y percibir ingresos por esa labor. Sucedería lo contrario si se legaliza (Fiorentini, 2000, pp. 445-446). Buchanan (1973; citado en Backhaus, 1979, pp. 623-631), por su parte, propone una represión no severa. Si el crimen organizado es una empresa que monopoliza un mercado ilegal, buscará restringir la oferta de su producto e impedir el ingreso de otros competidores para aumentar el precio de venta y los beneficios percibidos. Entonces, se desviarían menos recursos de la producción legal hacia la ilegal que en un mercado ilegal competitivo, surgido de una atomización de la oferta provocada por la represión estatal.

Por supuesto, la discusión sobre lo que es un bien o un mal en una sociedad va más allá de la eficiencia económica y la cuantificación monetaria o real de costos sociales. Involucra consideraciones de orden moral y cultural que son concretadas 
en una decisión política. No existe una conducta que sea criminal por naturaleza (Beltrán y Silva, 2006, p. 282). Durante la época de la Inquisición fueron torturadas personas que cuestionaron dogmas de fe de la religión Católica (Gaitán, 2006, p. 239) y, sin embargo, hoy estaríamos lejos de aceptar estas acciones. Al parecer, la figura del crimen organizado y su connotación jurídica ha sido considerada desde que algunas organizaciones delictivas fueron percibidas como una amenaza sobresaliente al orden institucional imperante. Según Beltrán y Silva (2006, pp. 282, 285), así sucedió con la Cossa Nostra (mafia italiana) en los Estados Unidos y en Colombia ante la aparición de los Carteles de la Droga.

Ha sido problemático definir qué hace organizadas a las actividades consideradas criminales; al punto que Beltrán y Silva (2006, pp. 291-292) sugieren una noción de crimen organizado por convención, es decir, de acuerdo a la comprensión generalizada que tienen sobre el particular los formadores de opinión (medios de comunicación) o las voces que suelen ser autorizadas en estos temas (políticos o policías).

Para Hagan (2006, pp. 127-133), la discusión entre criminólogos, sociólogos o autores de escritos sobre justicia criminal ha sido sobre los atributos que distinguen al crimen organizado de la denominada delincuencia común. Según el mismo autor, los atributos asignados al crimen organizado con mayor frecuencia son: concurso de empresas delictivas, capacidad para efectuar acciones violentas y para disuadir a la justicia y a la policía, ausencia de propósitos ideológicos en su interior, monopolización de un mercado ilegal y una estructura jerárquica ${ }^{1}$. Sin embargo, ¿depende la presencia de estos atributos del grado de complejidad de las actividades delictivas emprendidas?

Finckenauer (2005, p. 75) presenta el ejemplo de una "cadena de fraude de seguros que parecería compleja y organizada y, sin embargo, no usaron violencia, ni monopolizaron mercados o corrompieron oficiales, y sus integrantes ejercían profesiones legales". Todo delito, por sencillo que parezca, requiere algún grado de planificación y de organización, independiente que sea cometido por una o más personas. De ahí que para Beltrán y Silva (2006, p. 288) no sea clara la distinción entre lo organizado o desorganizado del crimen, poniendo en duda una definición para el crimen organizado. Hagan (2006, pp. 134-136) intenta superar esta dificultad y propone una distinción entre actividades y grupos de crimen organizado. Las primeras pueden demandar una organización, aunque no sean efectuadas por grupos organizados. Aún así volvemos al punto de la crítica de Beltrán y Silva.

Otro atributo del crimen organizado que resalta Schelling (1971, pp. 71-84) es la provisión de protección y de justicia (governance, en palabras de Fiorentini, 2000, p. 434) en el ámbito de la ilegalidad, por parte de una organización especializada en estas labores. Aunque también podría ser de forma descentralizada, en

1 En la ciudad de Bogotá (capital de Colombia), la Policía Metropolitana considera los atributos: división del trabajo, estructura jerárquica, existencia de un fin común que distinga a la organización, vinculación a una red de comercialización de bienes ilegales, destrezas criminales de los integrantes, empleo de medios técnicos y de armamento y contactos políticos (Entrevista a oficial del Centro de Investigaciones Criminológicas de la Policía Metropolitana de Bogotá - CICRI-MEBOG-). 
una estructura de red. Como en cualquier mercado, quienes efectúan transacciones ilegales demandan una protección de los bienes que negocian y una garantía del cumplimiento de los precios, formas de pago y características pactadas de estos bienes (Backhaus, 1979, pp. 625-628). En última instancia, un sistema de reglas y de sanciones entre los participantes de mercados ilegales. En tanto este sistema amplíe su cobertura hacia un mayor número de oferentes y demandantes $-\mathrm{y}$ de mercados ilegales- mayores serán las economías de escala o ahorros en la defensa de 'unos' derechos de propiedad y en el acopio de información sobre clientes confiables (reducción de costos de transacción, en el lenguaje neoinstitucional).

Por lo tanto, puede emerger una organización con la tecnología militar suficiente para ejercer un monopolio de violencia y de justicia, a cambio de un pago, y que, además, seleccione la entrada de nuevos oferentes en determinados mercados ilegales y disuada el control de las autoridades del Estado. Otra posibilidad es la de un crimen organizado integrado por una red de empresas ilegales que comparten un sistema de reglas, y en el que cada una asume parte de los costos de sostenimiento de tal sistema y los cubre con cargo a los precios de 'sus' mercancías. Así podría suceder entre quienes se dedican a actividades delictivas de tipo apropiativo (Dick, 1995; citado en Fiorentini, 2000, p. 451), como los hurtos o delitos contra el patrimonio que maneja la Policía Metropolitana de Bogotá, pues demandan algún grado de tecnología militar para su desempeño que, en un momento dado, les puede servir de autoprotección, aunque no hasta alcanzar una posición monopólica en la provisión de servicios de governance.

La competencia violenta por el monopolio de rentas ilegales por parte de organizaciones con alcance internacional, como las Mafias italianas, las Triadas de China y los carteles colombianos de la droga (Allum y Sands, 2004, pp. 137-152), opaca el poder que les confiere el uso de la fuerza para imponer o promover normas informales de conducta en el desarrollo de negocios ilegales y de la vida económica en general. Según los mismos autores, estas normas y sus identidades culturales serían una, sino la principal, fortaleza del crimen organizado que opera en Europa para extender y diversificar sus actividades en el continente, e incluso para entablar acuerdos de cooperación con grupos de distintas nacionalidades. Entonces, hay evidencia que apunta a que el "negocio" (en palabras de Schelling) o el atributo que distingue a un crimen organizado puede ser, como ya lo hemos anotado, el soporte en un sistema de reglas y penalizaciones para el funcionamiento de mercados ilegales.

Un crimen organizado-regulado encuentra fundamento en la idea de divergencia que plantea Silva (2006, pp. 296-314) para definir las conductas criminales de forma alternativa a la idea de desviación, dominante en la criminología. Las funciones de protección y de justicia que detenta el crimen organizado pueden ser divergentes al orden social instituido por el Estado, pues expresan intereses, valores, creencias y actitudes distintos y, en consecuencia, son declaradas ilegales. 
En cambio, un orden divergente y alternativo queda descartado cuando asumimos que un crimen o delito ${ }^{2}$ es una conducta desviada o anormal pues, a priori, esa conducta queda descalificada y no se discute la legitimidad de aquellas consideradas legales. Tampoco se evalúa si las legales son prácticas generalizadas entre la población y la contraposición de intereses y valores entre las legales e ilegales. Si tratamos de demostrar que una conducta criminal es desviada validamos las no criminales y el debate sobre el crimen organizado se restringe a su grado de planificación, en cuanto a actividades u organizaciones, y no permite estudiar su capacidad de resistencia y de funcionalidad hacia el orden político imperante.

¿Qué posibilidades de desarrollo, en ámbitos urbanos, tiene un crimen organizado que soporta servicios de governance, es decir, que detenta un monopolio de la violencia y de la justicia? Al respecto, es poco lo que se ha dicho desde el campo de la llamada criminología socioespacial. Podemos comenzar, por ahora, con las aportaciones en este campo sobre la distribución espacial del crimen urbano.

\section{Algunas teorías sobre la distribución espacial ${ }^{3}$ del crimen urbano}

\section{Teoría del desorden social}

Las comunidades y vecindarios con un elevado grado de privación económico y social, explosión demográfica, movilidad residencial, descomposición familiar, urbanización o heterogeneidad étnica son más propensas a presentar tasas elevadas de criminalidad. De acuerdo a los precursores de esta teoría (Shaw y McKay, 1942; citados en Bottoms y Wiles, 2002, pp. 621-623), la influencia de los factores mencionados en las conductas criminales estaría mediada por la ausencia de una cultura colectiva que expresara y reprodujera los valores de quienes residían en estos vecindarios. Valores que permitirían una neutralización del crimen.

Una versión ampliada de la teoría (Sampson, Raudenbush y Earls, 1997; citados en Bottoms y Wiles, 2002, pp. 643-644) sugiere denominarla "falta de eficacia colectiva”. Es decir, existe una débil capacidad organizacional al interior de una comunidad para inhibir comportamientos delictivos, en especial, de niños(as) y jóvenes. Esta versión de la teoría comparte la idea de capital social de Putnam (1993; citado en Siisiäinen, 2000, pp. 3-9), quien alude a la confianza, normas sociales, obligaciones recíprocas y asociaciones voluntarias presentes, para el caso, entre los residentes de un vecindario. La delincuencia sería uno de los resultados del deterioro del capital social o de un incipiente estado del mismo. Otros autores, como Gaviria (1998), hablan de un capital social perverso; es decir, de redes delincuenciales que se expanden y reproducen porque representan una posibilidad de ascenso social

2 Dentro de nuestra exposición no es necesario diferenciar entre crimen y delito en términos de la gravedad con que se cometieron, como sí sucede en el derecho francés (Silva , 2006, p. 299).

3 A partir de dos componentes: estructura y procesos. El primero hace alusión a las organizaciones o disposición funcional de objetos en un espacio físico y, el segundo, a los mecanismos que permiten la estructura. Ambos componentes se pueden retroalimentar, pues la estructura también incide en la forma en que se desarrollan los procesos y sus posibilidades de cambio. 
expedita para los jóvenes. Además, el tamaño de las redes contribuye a congestionar el sistema de justicia, y la participación en éstas de autoridades judiciales o policiales aportan al aumento de los niveles de impunidad.

Los apelativos de perverso o (des)orden social llevan la misma connotación negativa implícita en la criminología, cuando su objeto de estudio es una conducta desviada, mas no divergente. Las condiciones y los alcances de expansión y reproducción del capital social perverso, que menciona Gaviria (1998), invitan a pensar en si ese tipo de capital puede ser un hecho marginal o si adquiere tal nivel de generalización que el apelativo de "perverso" queda en entredicho y, entonces, habría que indagar para quién es perverso. El capital es un concepto dinámico ${ }^{4}$ que no se reduce a la valoración estática de un instante, que se impone sobre lo sucedido en el pasado y lo que ha de seguir en el futuro. En términos políticos, no se restringe a la valoración de un statu quo sobre un orden legal (legítimo) y unas cuantas conductas (des)ordenadas (desviadas).

Por el contrario, Bourdieu (1980; citado en Siisiäinen, 2000, pp. 9-19), antes que Putnam (1993), estableció que las redes de asociación que conforman el capital social hacen de canales de transmisión de otras formas de capital (cultural, simbólico y económico), que sirven -y por eso representan un capital- para sostener estructuras de poder que no tendrían que ser inmutables. El capital social sería un sistema de interconexiones de individuos y grupos que, en forma permanente, les permite definir y redefinir posiciones en una distribución y redistribución del poder al interior de una sociedad o población. En una sociedad con patrones colectivos de conducta que se perciben de manera continua (incluidos los consignados en sus marcos jurídicos), la sensación de redistribución (cambio) del poder tiende a ser pequeña; lo mismo que la referida a las variaciones en la estructura y volumen de los capitales, que trata Bourdieu, de individuos y grupos. Pero, en una donde la sensación de cambio es alta y la percepción de referentes colectivos estables es débil, lo común sería la emergencia y cesación de órdenes sociales alternativos (por ejemplo, crimen organizado) al ofrecido desde un Estado que, así planteado, también sería débil.

\section{Teoría de actividades rutinarias}

Los exponentes de esta teoría (Cohen y Felson, 1979; citados en Bottoms y Wiles, 2002, pp. 629-630) intentan identificar condiciones de vulnerabilidad frente al crimen en las actividades cotidianas de las personas. Estas actividades incluyen, en general, lugares de vivienda, trabajo, estudio, diversión o de consumo y de producción, además del desplazamiento entre los mismos. La vulnerabilidad incluye las condiciones de protección para contrarrestar la acción de agresores motivados, quienes, a su vez, gozan de unas rutinas de conocimiento y de experticia para detectar los objetivos adecuados, en términos de su valor, facilidades de transporte y accesibilidad (Bottom y Wiles, 2002, pp. 629-630).

Proviene de la economía y alude a un proceso temporal de acumulación (ahorro) que, en un momento dado, es incorporado a la producción de otros bienes, valorados por el flujo monetario de rentas esperadas que se obtienen de su venta. 
En la teoría de actividades rutinarias, se acunó el término "espacio defendible" para identificar los controles disponibles en una comunidad para resguardar su espacio vital de la delincuencia. La defensa puede ser un indicador de apropiación territorial, es decir, del intento de un grupo humano por derivar de un espacio un sentido funcional (uso exclusivo) y simbólico (identidad) (Rocke, 2002, p. 63); sin embargo, no es clara una indagación sobre territorialidad si, como declara Rocke (2002, p. 64), la teoría se ha centrado en controles formales (por ejemplo, aquellos de tipo legal que no regulan situaciones específicas de tiempo y lugar) y descuidado los informales (producto de la interacción con un medio en particular) a los que acuden las comunidades para defender los espacios en los que se desenvuelven.

Además, es difícil comprender la defensa o el grado de vulnerabilidad si no se entiende la amenaza: ¿qué motiva a los agresores? Tema que, también comentan Bottom y Wiles (2002, p. 630), ha tenido poca importancia dentro de la teoría. Según Rocke (2002, pp. 59-61), esta teoría ha sido influenciada por un análisis económico que considera al potencial criminal como un individuo, amoral y asocial, que hace una valoración costo-beneficio de evadir los mecanismos de control del crimen y que actúa en consecuencia. De esta manera, es obviada toda consideración normativa, ideológica o emocional del potencial criminal para tomar una decisión, y los conocimientos, conductas y visiones que ha adoptado como guía en su entorno social.

\section{¿Es posible integrar ambas teorias?}

La versión ampliada del desorden social sugiere una posibilidad promisoria. El deterioro sobre la percepción de seguridad de un vecindario podría estar asociado a la mencionada debilidad en su capacidad organizacional para afrontar actividades criminales, ya sea que los agresores habiten allí mismo o provengan de otros sectores urbanos. En otras palabras, hay una condición de vulnerabilidad en el vecindario que permite la emergencia o la atracción del crimen y de sus ejecutores.

Las personas sostienen y reproducen o, por el contrario, debilitan un orden colectivo en el vecindario que residen y frecuentan mediante las actividades rutinarias que practican en sus vidas diarias. En estas actividades se evidencia qué tanto las personas han incorporado medidas (capacidad organizacional) de autoprotección, vigilancia y coordinación entre ellas y con las autoridades, para prevenir y reprimir actos delictivos de acuerdo, además, a los factores socioeconómicos y habitacionales que las afectan. Bajo este planteamiento, lo delictivo no se reduce a la violación de la ley (formal), pues involucra la trasgresión de un orden colectivo y de sus códigos informales de conducta.

Un factor que incide en las rutinas de una comunidad y en su capacidad de respuesta frente al crimen es el cambio en el uso de un suelo urbano. Por ejemplo, de residencial a comercial y de negocios. En este caso, ingresa una población flotante, trabajadora o consumidora, que se vuelve blanco para los ladrones de bienes y de objetos personales. Las familias que aún residen en el sector acuerdan ahora formas de protección distintas con personas también distintas en cuanto a 
los activos que están en riesgo y pretenden defender, lo que redunda en dificultades para llegar y sostener estos acuerdos. Este ejemplo sería parte de la hipótesis de los vecindarios en transición, donde se producen aumentos de la criminalidad debido a cambios en el mercado inmobiliario. Cambios que se relacionan con variaciones en las actividades económicas de los vecindarios, la llegada y salida de población y alteraciones en los avalúos y precios de las viviendas y de los bienes inmuebles en general.

No obstante, la transición de un vecindario no es, en sí misma, una señal de deterioro. Es una oportunidad para procesos desarticuladores o cohesivos de diversa índole, y para aumentar o disminuir el margen de acción de un orden criminal en una comunidad. En ello incide la percepción que cada uno de los habitantes y asistentes frecuentes del vecindario tenga sobre el momento de transición y sobre la capacidad organizacional de la comunidad para afrontarlo. Estas percepciones incluyen las expectativas que se forman entre las personas acerca de las decisiones de los demás sobre si revitalizar o abandonar la comunidad, hasta que la mayoría de las expectativas se unifica en una de estas direcciones.

Aun así, un vecindario deteriorado sí reflejaría una comunidad desarticulada. Estas comunidades no pueden hacer resistencia colectiva (débil capacidad organizacional) a las amenazas criminales externas y no pueden evitar la infiltración criminal, pues la desconfianza entre sus integrantes dificulta la detección de, por ejemplo, un ladrón cuando todos los residentes del vecindario son potenciales sospechosos.

Ahora bien, ¿qué sucede si la capacidad organizacional surge del crimen organizado? Bottoms y Wiles (2002, p. 644) evaden esta pregunta y sólo hablan de la capacidad organizacional de los no criminales. Esta salida de tipo normativo no es satisfactoria, pues no basta decir que el desorden de la gente buena es aprovechado por la gente mala (criminal o desviada). Puede suceder, por ejemplo, que se geste una alianza entre el crimen organizado y un determinado segmento de la población urbana para proteger intereses económicos conjuntos; o que exista un copamiento territorial de parte del crimen organizado sobre espacios segregados por las personas de más altos ingresos. Estos ejemplos revelarían que el crimen organizado se distribuye de modo desigual por la ciudad de acuerdo a modos de sociabilidad discriminados por tipos de vecindario. La vida de vecindario, o el vecindario en sí mismo, depende de esa sociabilidad entre sus habitantes.

\section{Aproximación metodológica a los vecindarios vulnerables al crimen organizado en Bogotá}

Una expresión del crimen organizado es el homicidio común, pues es una de las sanciones típicas de la violación de sus acuerdos internos, que puede ser extendida al control de actividades legales y a la regulación de la vida cotidiana de la gente. A partir del año 2007, existen registros completos de los móviles preliminares ${ }^{5}$ de las

En primera etapa de investigación judicial. 
muertes en Bogotá. Desde entonces, y hasta 2009, dos localidades concentraron la tercera parte de los asesinatos, de diecinueve en que fue dividida la ciudad con fines político-administrativos. Ciudad Bolívar y Kennedy, ubicadas al sur y suroccidente, son las únicas localidades con un nivel de participación significativo ${ }^{6}$ (Cuadro 1 ), por encima de la media (5,3\%; más o menos el 2,8\%). Los homicidios del crimen organizado son planificados, y de éstos se deduce un patrón espacial. Entonces, ¿se concentra el crimen organizado en Ciudad Bolívar y Kennedy? Al respecto, se destaca que los delitos contra el patrimonio económico suceden hacia el norte y nororiente de Bogotá (CICRI-MEBOG, 2009, pp. 42-88), donde habitan personas con una condición socioeconómica media y alta (estratos 4 al 6 , según la clasificación empleada por el gobierno de la ciudad). Entre tales delitos, el hurto a residencias puede servir para develar formas distintas de inserción del crimen organizado en los hogares y vecindarios más acomodados.

CUADRO 1 | Distribución porcentual de los homicidios comunes y hurtos a residencias en Bogotá (años 2007-2009)

\begin{tabular}{|c|c|c|}
\hline LOCALIDAD & HOMICIDIOS COMUNES & HURTOS A RESIDENCIAS \\
\hline USAQUÉN & 4,4 & 11,9 \\
\hline Chapinero & 1,2 & 8,6 \\
\hline SANTA FE & 5,1 & 2,2 \\
\hline SAN CRISTÓBAL & 6,1 & 3,1 \\
\hline Usme & 5,9 & 2,4 \\
\hline Tunjuelito & 2,3 & 1,2 \\
\hline Bosa & 5,9 & 4,1 \\
\hline KENNEDY & 15,2 & 10,6 \\
\hline FONTIBÓN & 2,5 & 4,2 \\
\hline ENGATIVÁ & 6,9 & 9,3 \\
\hline SUba & 8,3 & 18,6 \\
\hline BARRIOS UNIDOS & 2,1 & 3,9 \\
\hline Teusaquillo & 1,4 & 5,1 \\
\hline Los Mártires & 5,2 & 1,1 \\
\hline ANTONIO NARIÑo & 1,6 & 1,4 \\
\hline Puente Aranda & 2,7 & 3,0 \\
\hline La Candelaria & 0,5 & 0,6 \\
\hline RAFAeL URIBE URIBE & 7,0 & 2,8 \\
\hline Ciudad Bolívar & 15,8 & 5,8 \\
\hline Total Bogotá & 100,0 & 100,0 \\
\hline
\end{tabular}

FUENTE ELABORACIÓN PROPIA. DATOS SUMINISTRADOS POR EL CICRI-MEBOG, SUJETOS A VARIACIÓN.

Suba, Usaquén, Kennedy, Engativá y Chapinero presentan una participación significativa ${ }^{7}$ (Cuadro 1) por encima de la media (5,3\%; más o menos el 3,1\%) de hurtos a residencias en la ciudad. Salvo Kennedy, las restantes se encuentran al norte y suman el 48,4\% de los casos, del año 2007 al 2009. Sin embargo, las

6 En un intervalo de confianza del $99 \%$.

7 En un intervalo de confianza del $99 \%$. 
presuntas modalidades ${ }^{8}$ de hurtos a residencias y móviles de homicidios difieren al interior de las localidades (Anexos A1 y A2). Las condiciones de vida en cada una también son distintas. En consecuencia, desde la administración distrital (gobierno de la ciudad) se delimitaron unidades de planeación zonal (UPZ) con una relativa homogeneidad socioeconómica interna que, a su vez, permitiera distinguir unidades entre sí. Luego se creó una tipología de las UPZ para facilitar la focalización de los recursos públicos.

Hemos elaborado gráficos de densidad de homicidios y hurtos a residencias, sobrepuesto a la tipología de UPZ (Figuras 1 y 2), para precisar la ubicación de estos delitos en las localidades y guiar la indagación de campo acerca de las características de los vecindarios afectados, y de la interacción de sus habitantes que facilitaran la presencia del crimen organizado. La tipología de UPZ sirvió de referencia para construir un conjunto propio de categorías de clasificación de los vecindarios en función del objeto de estudio (crimen organizado) y para entender las modalidades delictivas en que se manifiesta.

FIGURA 1 | Densidad de homicidios comunes en Bogotá (años 2007-2009)

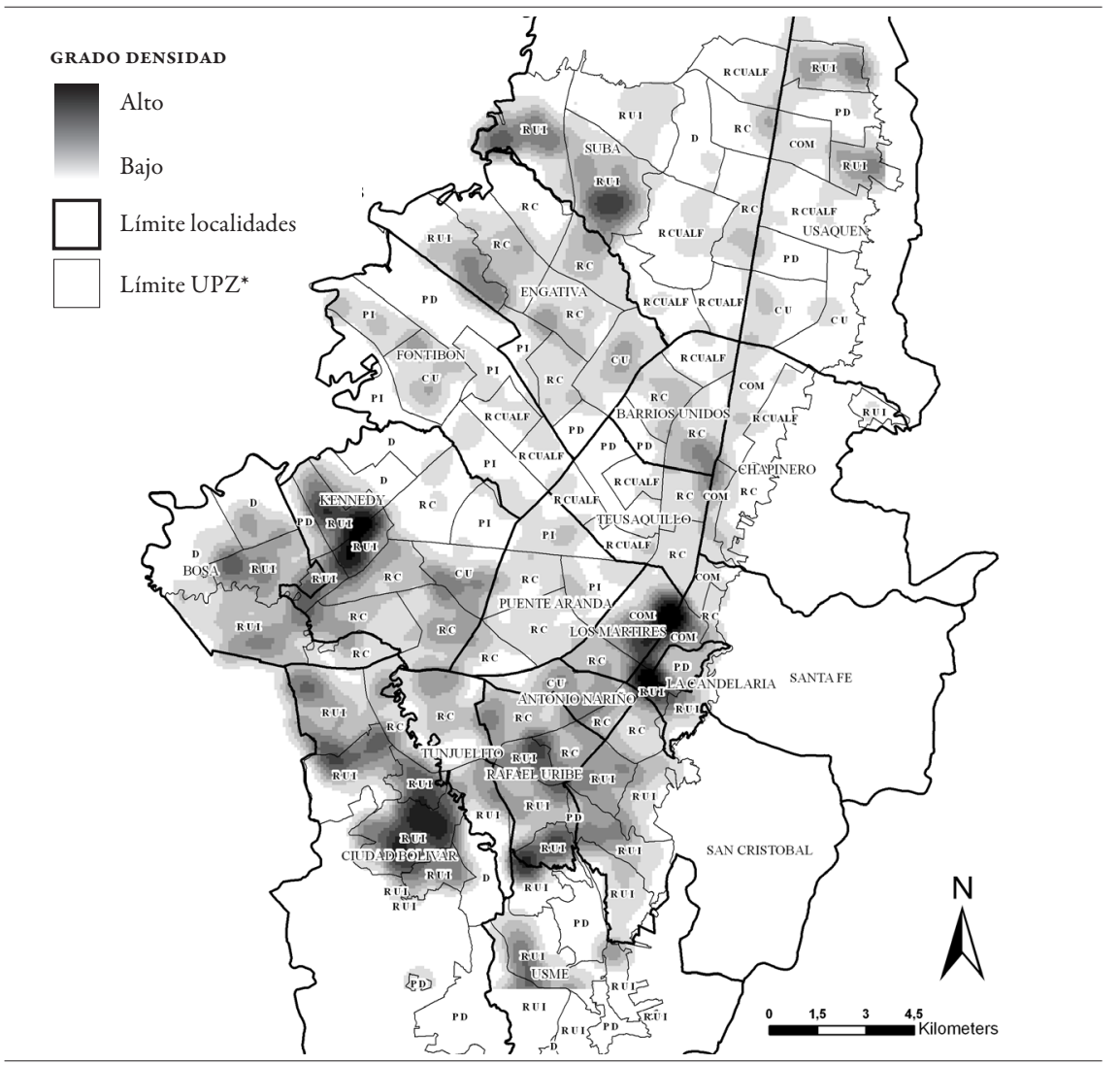

FUENTE ELABORACIÓN PROPIA. BASES CARTOGRÁFICAS SUMINISTRADAS EN EL OBSERVATORIO DE CRIMINALIDAD DE LA MEBOG.

En el registro de casos de hurtos, la policía consigna la modalidad en vez de la causa o móvil. 
FIGURA 2 | Densidad de hurtos a residencias en Bogotá (años 2007-2009)

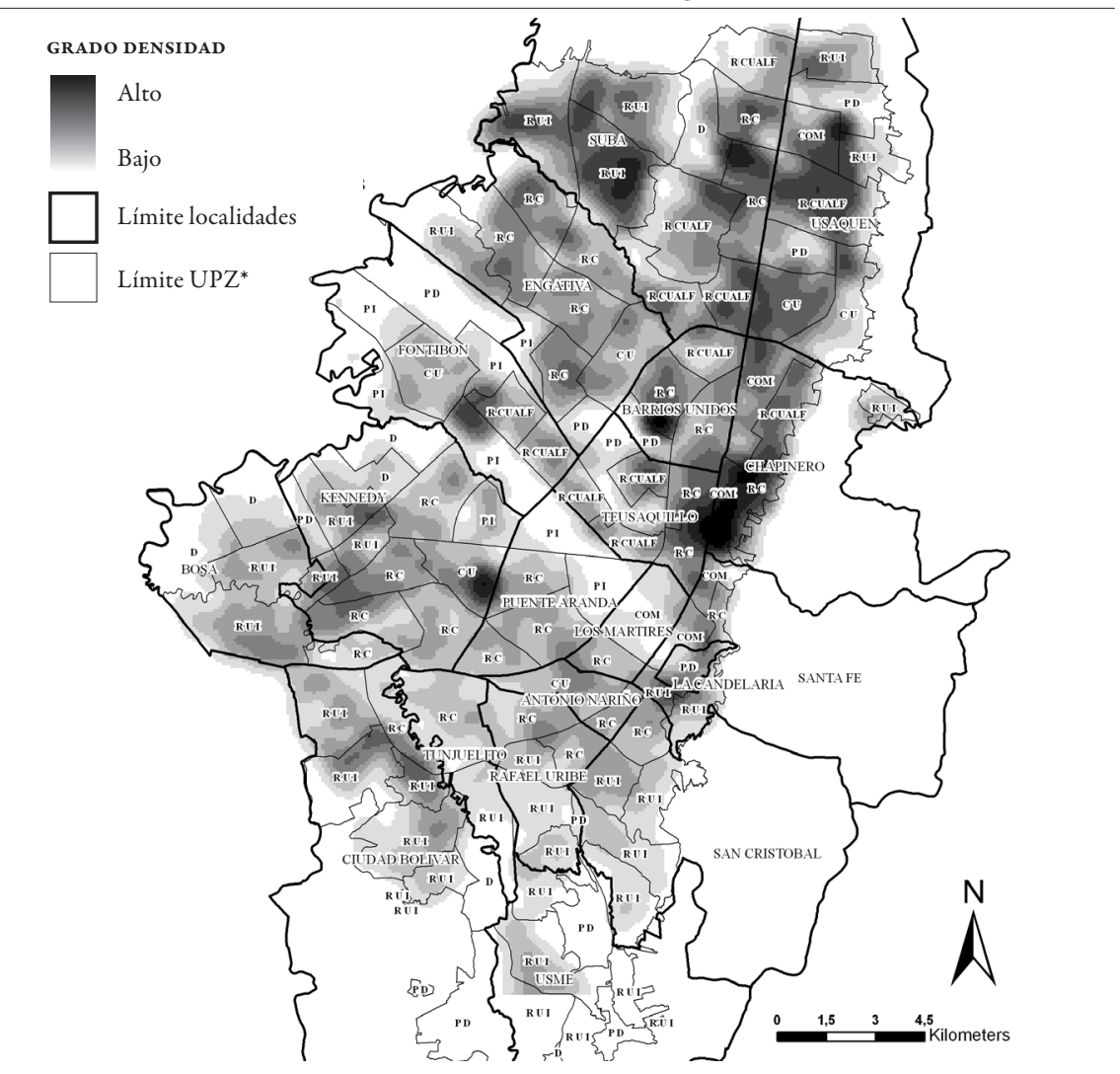

FUENTE ELABORACIÓN PROPIA. BASES CARTOGRÁFICAS SUMINISTRADAS EN EL OBSERVATORIO DE CRIMINALIDAD DE LA MEBOG.

* -Tipología UPZ - Residencial de urbanización incompleta (R U I): sectores periféricos no consolidados, en estratos 1 y 2 , de uso residencial predominante con deficiencias en infraestructura, accesibilidad, equipamientos y espacio público. Residencial consolidado $(R C)$ : sectores consolidados de estratos medios de uso residencial predominante. Se presenta un cambio de usos y un aumento no planificado en la ocupación territorial. Residencial cualificado ( $R$ CUALF): sectores consolidados de estratos medios y altos con uso residencial; cuentan con infraestructura de espacio público, equipamientos colectivos y condiciones de hábitat y ambiente adecuadas. Desarrollo $(D)$ : sectores poco desarrollados, con grandes predios desocupados. Con centralidad urbana $(C U)$ : sectores consolidados con centros urbanos y el uso residencial dominante ha sido desplazado por usos que fomentan la actividad económica. Comerciales (COM): sectores del Centro metropolitano. Destinados a actividades económicas terciarias de intercambio de bienes y servicios (locales y oficinas). Predominantemente Industrial (P I): la actividad principal es la industria, aunque hay comercio y lugares productores de dotación urbana. Predominio dotacional ( $P D)$ : grandes áreas para producción de equipamientos urbanos y metropolitanos que, por su magnitud relativa, tienen un manejo especial (Secretaría Distrital de Planeación -SDP_-). 
En campo se efectuaron observaciones participantes y entrevistas, semiestructuradas y a profundidad a: policías del cuerpo de oficiales y del nivel ejecutivo que vigilan los sectores estudiados de Bogotá, a efectivos de policía judicial que investigan homicidios y hurtos a residencias, a líderes comunitarios y a víctimas. Ante las limitaciones de recursos, incluido el tiempo, se indagó en detalle a personas con un volumen de información representativo, a riesgo de carecer de una muestra estadística de entrevistados. En la argumentación de los hallazgos cualitativos se han empleado algunos datos de apoyo, a nivel de localidades, pues la mayoría de la información oficial cuantitativa se basa en esta unidad espacial de agregación, mientras que la de UPZ está en construcción.

\section{Hallazgos y análisis}

Los homicidios de Ciudad Bolívar suceden en vecindarios periféricos. De acuerdo a la tipología de UPZ, son sectores residenciales de urbanización incompleta. Según Hataya (2009), los vecindarios periféricos se caracterizan por una historia de asentamiento irregular y de autoconstrucción de las viviendas. En sus orígenes, violaban la normatividad urbanística, pues se encontraban fuera del perímetro urbano, carecían de los espacios públicos estipulados para el trazado de vías y andenes, zona verde o de recreación y deporte, y sus conexiones a las redes de servicios domiciliarios (por ejemplo, agua potable, energía eléctrica) eran clandestinas. Aun así, el asentamiento era legal, ya que el loteo para vivienda lo había hecho un urbanizador (pirata), quien había adquirido los terrenos lícitamente o los negociaba en acuerdo con el terrateniente.

Los asentamientos irregulares fueron una alternativa para acceder a vivienda, ya que las opciones ofrecidas desde el gobierno nacional o distrital eran costosas o insuficientes frente a la demanda de personas regidas por una lógica de necesidad (Cuadro 2, columnas A, C y D). Personas aún sin capacidad estable de endeudamiento por su flujo volátil de ingresos y ubicación laboral inconstante. Los habitantes de vecindarios periféricos 9 suelen trabajar en la economía informal ${ }^{10}$ (Cuadro 2, columna E), cuyos oficios requieren una baja calificación laboral y carecen del acceso garantizado a servicios de salud y ahorro pensional de calidad ${ }^{11}$. Una manifestación de la informalidad es la apertura de locales comerciales en las primeras plantas de las viviendas, entre los cuales funcionan sitios de baile y de venta y consumo de bebidas alcohólicas.

9 Entre ellos se encuentran migrantes con un pasado violento, porque fueron desplazados a la fuerza de sus lugares de origen o integraron alguna agrupación armada ilegal (guerrillas y su contraparte, los paramilitares) y ahora son considerados desmovilizados.

10 Ocupados informales son: "(1) los empleados particulares y los obreros que laboran en establecimientos, negocios o empresas que ocupen hasta cinco personas en todas sus agencias y sucursales, incluyendo al patrono y/o socio; (2) los trabajadores familiares sin remuneración; (3) los trabajadores sin remuneración en empresas o negocios de otros hogares; (4) los empleados domésticos; (5) los jornaleros o peones; (6) los trabajadores por cuenta propia que laboran en establecimientos hasta cinco personas, excepto los independientes profesionales; (7) los patrones o empleadores en empresas de cinco trabajadores o menos; (8) se excluyen los obreros o empleados del gobierno" (Departamento Administrativo Nacional de Estadística -DANE-, 2010, pp. 11-12). En Bogotá, la proporción media trimestral móvil de trabajadores informales es de 51,9\% durante el período 2007-2008.

11 El promedio, entre localidades, de trabajadores por cuenta propia afiliados a un fondo de pensiones es de 13,7\% (DANE-SDP, Encuesta de Calidad de Vida de Bogotá, 2007). 
CUADRO 2 | Características demográficas y socioeconómicas de localidades bogotanas

\begin{tabular}{|c|c|c|c|c|c|}
\hline LOCALIDAD & $\begin{array}{c}\text { TASA } \\
\text { MEDIA DE } \\
\text { CRECIMIENTO } \\
\text { (x 1.000 HAB.) } \\
\text { Años } 2005-2010\end{array}$ & $\begin{array}{c}\text { PoBlación } \\
\text { 15-24 AÑos } \\
\text { DE EDAD (\%) } \\
\text { Año } 2007\end{array}$ & $\begin{array}{c}\text { DENSIDAD } \\
\text { URBANA } \\
\text { (PERS./HA.) } \\
\text { Año } 2009\end{array}$ & $\begin{array}{c}\text { HOGARES EN } \\
\text { POBREZA (\%) } \\
\text { Año } 2007\end{array}$ & $\begin{array}{c}\text { Trabajadores } \\
\text { POR CUENTA } \\
\text { PROPIA (\%) } \\
\text { Año } 2007\end{array}$ \\
\hline USAQUÉN & 10,8 & 17,1 & 121 & 10,1 & 21,6 \\
\hline Chapinero & 9,8 & 18,4 & 99 & 10,4 & 18,2 \\
\hline Santa Fe & 0,4 & 18,3 & 149 & 31 & 31,8 \\
\hline SAN CRIStóbAL & $-1,2$ & 18,6 & 249 & 32,3 & 21,9 \\
\hline Usme & 40,2 & 19,8 & 115 & 38 & 21,5 \\
\hline Tunjuelito & $-1,4$ & 18 & 205 & 28,7 & 21,9 \\
\hline Bosa & 28,4 & 18,3 & 232 & 31,4 & 19,3 \\
\hline KenNedy & 12,9 & 17,9 & 259 & 23 & 22,8 \\
\hline FONTIBÓN & 26,2 & 17,2 & 99 & 15,5 & 18,3 \\
\hline ENGativá & 10,2 & 17,4 & 231 & 15,7 & 22,6 \\
\hline Suba & 26,3 & 17,4 & 162 & 15,3 & 20 \\
\hline BARRIOS UNIDOS & 7,8 & 15,9 & 194 & 13,5 & 25 \\
\hline Teusaquillo & 9,3 & 17,5 & 101 & 6,6 & 22,5 \\
\hline Los Mártires & 3,2 & 17,8 & 149 & 21,8 & 34,1 \\
\hline ANTONIO NARIÑo & 2,2 & 18,2 & 221 & 21,6 & 29,3 \\
\hline Puente Aranda & 0,6 & 17,3 & 149 & 15,9 & 22 \\
\hline La CANDELARIA & 0,8 & 17,6 & 117 & 20,3 & 32,3 \\
\hline RAFAEL URIBE URIBE & $-0,8$ & 18,7 & 272 & 40 & 18,6 \\
\hline Ciudad Bolívar & 20,1 & 19,2 & 182 & 44,7 & 19,6 \\
\hline Total Bogotá & & 17,9 & 175 & 22,8 & 21,6 \\
\hline
\end{tabular}

FUENTE ELABORACIÓN PROPIA. DATOS DE SDP, y DANE-SDP, ENCUESTA DE CALIDAD DE VIDA DE BOGOTÁ, 2007.

Las mejoras vigentes en las viviendas, en accesibilidad (arreglo de vías y andenes, conexión a la red vial principal de Bogotá) y en habitabilidad (dotación de servicios domiciliarios) fueron resultado de la organización colectiva para constituir una instancia de decisión (Junta de Acción Comunal), movilizar mano de obra propia, presionar por vías de hecho (protestas, bloqueos, marchas) la atención del gobierno distrital y negociar con políticos intermediarios a cambio de votos (clientelismo). Además, desde la administración distrital se adelantaron medidas para sanear las finanzas de las empresas de servicios domiciliarios, abrirlas a la participación privada y racionalizar su oferta bajo criterios de costo-beneficio. Con el tiempo, la opción menos costosa para responder a la demanda de vivienda y de hábitat en general fue regularizar los asentamientos y responder, paulatinamente, a las demandas básicas de sus residentes (Hataya, 2009). En la actualidad, se han hecho inversiones públicas en construcción de centros educativos, espacios públicos y recreativos, promoción de comedores comunitarios, equipamientos policiales, entre otros (Figura 3). Sin embargo, persiste la morfología del espacio urbanizado. Las vías son estrechas 
y su trazado evidencia la ausencia de articulación con un plan de expansión de la ciudad. Existen múltiples callejones entre las viviendas sobre los terrenos de ladera que distinguen a Ciudad Bolívar.

FIGURA 3 | Índice de calidad de vida de localidades bogotanas

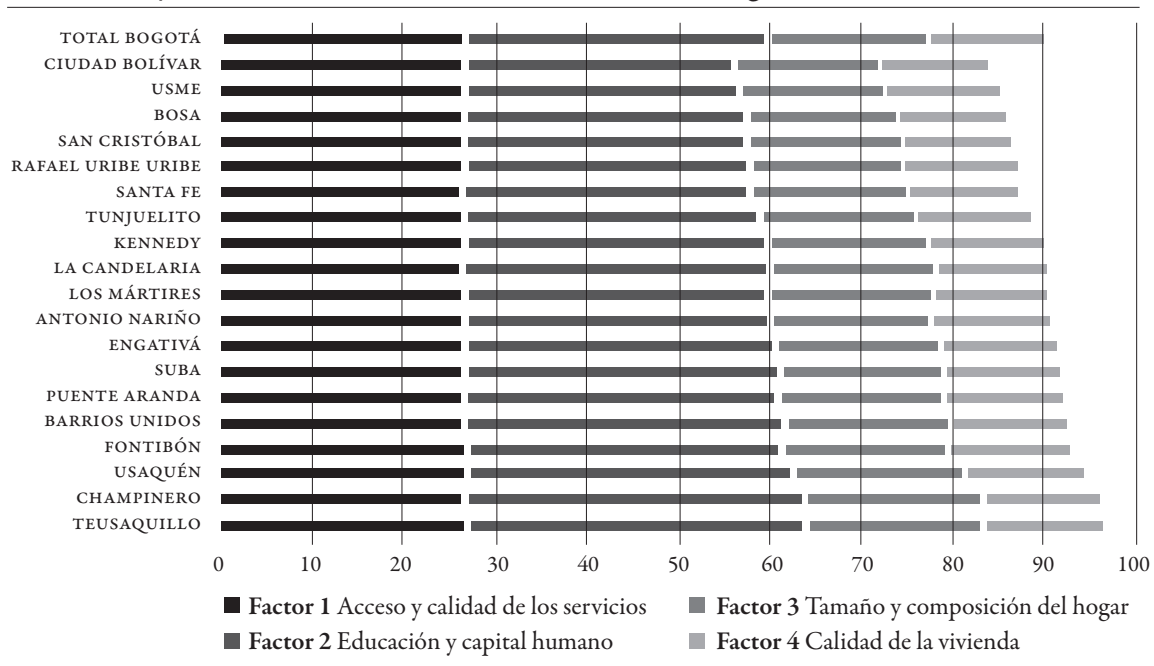

FUENTE ELABORACIÓN PROPIA. DATOS DE DANE-SDP, ENCUESTA DE CALIDAD DE VIDA DE BOGOTÁ, 2007.

La movilización social ha perdido fuerza, pues la gente considera que ha logrado mejoras básicas en su entorno y acceso a servicios esenciales. A pesar de las iniciativas del gobierno distrital por animar la participación comunitaria y controlar el clientelismo, los proyectos para el supuesto beneficio colectivo son diseñados a espaldas de los habitantes. La proporción de jefes de hogar de Ciudad Bolívar que perciben una mejora en la participación de las decisiones por parte de la comunidad es la más baja de Bogotá (11,5\% del total de jefes en la localidad; DANE-SDP, 2007) y la segunda más alta de los que perciben un empeoramiento $(21,9 \%$ del total de jefes en la localidad; DANE-SDP, 2007). Con respecto a la transparencia en el manejo de los recursos públicos, en Ciudad Bolívar se registra la segunda proporción más baja entre los que perciben una mejora (6,3\% del total de jefes en la localidad; DANE-SDP, 2007) y la menor de los que perciben un empeoramiento, aunque es del 42,3\% del total de jefes en la localidad (DANE-SDP, 2007). Por tanto, la capacidad de organización y compromiso colectivo para afrontar amenazas comunes se ve mermada a la espera de las soluciones que ofrezca el gobernante de turno. Una de las preocupaciones más sentidas es el consumo y tráfico de estupefacientes entre los jóvenes (Cuadro 2, columna B).

Los jóvenes suelen ser los más comprometidos en casos de homicidio. Las víctimas en Ciudad Bolívar de 15 a 24 años de edad suman 206 muertes, seguido del rango de 25 a 29 años de edad con 128 decesos entre los años 2007 y 2009, mientras que, para el mismo período, el $43,1 \%$ de capturados por homicidios por 
orden judicial en la localidad tienen entre 20 y 29 años de edad ${ }^{12}$. Algunos jóvenes participan en riñas a la salida de los sitios con venta de licor que funcionan como espacios de encuentro entre vecinos y desconocidos que laboran o consumen ocasionalmente en el vecindario. A su vez, son lugares para liberar tensiones y resolver diferencias (móviles personales, pasionales o familiares, en el registro policial) sin inhibiciones. Otros jóvenes hurtan a personas que lesionan de gravedad (móvil por burtarle) o son heridos por la reacción de sus víctimas (móvil por hurtar). También son afectados por ajustes de cuentas en desarrollo de actividades delictivas, como las extorsiones y el tráfico de estupefacientes, además de los hurtos (Cuadro A1).

Los jóvenes homicidas crecen en ambientes hostiles y asumen respuestas violentas a tensiones cotidianas, asimilando prácticas delictivas para satisfacer sus necesidades. Nacen, por lo general, de un embarazo indeseado entre padres también jóvenes y con una escolaridad básica, que debaten la decisión de abortar. Luego, la madre es abandonada o cría a sus hijos junto a una pareja violenta. De hecho, la mayor parte de homicidios por problemas familiares en la ciudad se producen en Ciudad Bolívar (Cuadro A1, columna C). La madre, sola o con su pareja, recurre a un trabajo no calificado, en sectores urbanos menos deprimidos, y deja a sus hijos solos gran parte del tiempo. Los niños crecen hasta su juventud en la calle y en los centros educativos, bajo la ley del más fuerte, con el deseo de asumir tempranamente roles de adultos, para ganar independencia económica y sobrevivir por su cuenta, a toda costa.

La comisión de delitos callejeros por algunos jóvenes convierte a este grupo poblacional en blanco de ajusticiamientos de parte de oferentes privados que son aceptados entre los habitantes de Ciudad Bolívar, pues rememoran las acciones de autodefensa que aún perviven en la mente de los primeros pobladores (Hataya, 2009), y porque se muestran más eficaces que la acción policial. También arremeten contra habitantes de calle, recicladores y vendedores callejeros ligados a la delincuencia en el imaginario colectivo. Así, adquieren el respaldo para ofrecer servicios de protección a comerciantes y a conductores de buses de transporte público afectados por ladrones, a cambio de una cuota ilegal (extorsiva), o para asesinar a alguien por una deuda pendiente, de tipo económico o de honor (por ejemplo, venganza pasional), previo acuerdo del pago por el homicidio. Sin embargo, la actividad más atractiva para deducir excedentes monetarios es la comercialización y venta al menudeo de estupefacientes, que les garantiza mayor capacidad bélica y de reclutamiento, además de regulación sobre los jóvenes que delinquen en estas localidades.

Los homicidios en la localidad de Kennedy se concentran, al igual que Ciudad Bolívar, en vecindarios considerados periféricos dentro de la tipología de las UPZ. Kennedy también se asemeja a Ciudad Bolívar en atributos demográficos, socioeconómicos (Cuadro 2) y en participación comunitaria. En los vecindarios afectados por el homicidio funciona la Central de Abastos de Alimentos de Bogotá (Corabastos), que ha sido foco de atracción de asentamientos irregulares desde su apertura en el año de 1972, y de mano de obra no calificada que se dedica a oficios informales, dentro o en torno a la Central. Ejemplos de oficios a su interior son ven-

Cálculos propios a partir de datos suministrados en el CICRI-MEBOG. 
dedor, almacenista, carguero, transportador de mercancías y de personas; afuera, la venta de mercancías atractivas para los clientes y trabajadores de la Central o el reciclaje de los desechos que allí se producen. Parte de los inmuebles residenciales, ya construidos y formalizados, se han convertido en sedes de negocios. De ahí que pueda ser considerado un vecindario en transición más que periférico. Un reconocimiento oficial al respecto es la propuesta de decreto de reglamentación de la UPZ, que contiene a Corabastos y lleva su nombre, formulada en 2009, en el que se contemplan usos comerciales y mixtos (residencial y comercial) del suelo.

La transición del vecindario ha servido para el arribo de mercados ilegales mediante un proceso en curso similar al culminado en el centro histórico de Bogotá, donde el uso predominante del suelo es comercial. En los alrededores de Corabastos se ha instalado una oferta de mercancías hurtadas -quizá usurpadas en el mismo sector- de estupefacientes, bebidas alcohólicas, armas de fuego para la venta o en alquiler, servicios sexuales y de diversión nocturna, a semejanza del centro histórico. Los homicidios han sido provocados por ladrones en el afán de reducir a sus víctimas -algunos para financiar su consumo de estupefacientes-, o los propios ladrones fueron asesinados, como resultado de riñas a la salida de establecimientos con venta de licor, o en desarrollo del tráfico y consumo de estupefacientes. Los comercializadores (jíbaros) de la droga (base de coca y marihuana) definen sectores de distribución, y sus límites son defendidos a muerte. A su vez, establecen una cuota de dinero en efectivo sobre las ventas al consumidor final de parte de los expendedores que conforman su clientela. Estas cuotas se garantizan con la propia vida. Los consumidores, por su parte, se pueden agredir fatalmente por obtener una dosis personal (bicha).

Los vecindarios del centro histórico, que comprende parte de las localidades de Los Mártires y Santa Fe, surgieron a partir de edificaciones residenciales que formaron parte del plan de expansión de la ciudad, con sus equipamientos y dotaciones respectivas. El arribo de los mercados ilegales se produjo a la par de la creación de una plaza comercial que se consolidó en el sector. Hoy se ofrecen allí productos de consumo final (perecederos y no perecederos) y de consumo intermedio, a bajo costo, para una clientela con una reducida capacidad de ingresos (Alfonso, 2009) o que compra al por mayor para la posterior reventa de los productos. Ello es posible porque, en parte, la mercancía ofrecida es de contrabando o hurtada, tales como teléfonos celulares, partes y repuestos de automotores y motocicletas. Otras actividades establecidas han sido talleres de mecánica, ferreterías, prostitución, sitios de baile y de venta de licor y tráfico de estupefacientes. El arribo de tales actividades, y de sus empleados y clientela respectiva, han estimulado el abandono de las viviendas que aún funcionan como residencias familiares; aunque han surgido inquilinatos, a dos mil pesos la noche, que sirven de estadía a delincuentes. Los expendios de estupefacientes (denominados ollas) funcionan en viviendas deterioradas que fueron vendidas o abandonadas por las familias de los propietarios originales, cuando éstos envejecieron o murieron y sus hijos se habían independizado del hogar. 
La combinación de la oferta de drogas, sexo y alcohol configura un entorno de negocios en el que se "combinan conductas legales e ilegales, que comparten un volumen permanente de clientela tal que desborda la capacidad de control de las autoridades", y sus ingresos en efectivo "facilitan la inversión de dineros obtenidos de modo ilícito” (Velásquez, 2010, p. 17). Son entornos que sirven de cubierta para los jíbaros y para el tránsito de mercancías con usos ilegales (estupefacientes, armas de fuego, precursores químicos) por parte de los narcotraficantes que se dedican a la exportación de cocaína. De hecho, Corabastos y el centro histórico son plazas comerciales de la ciudad con flujos permanentes - de doble vía- de bienes y servicios con otras partes de Colombia.

En el centro histórico, los jíbaros pagan vigilantes armados, vestidos de particular, denominados sayaeyines, que velan por el funcionamiento de las ollas. Portan pistolas, hasta con tres proveedores, legalizadas y, algunas, con permiso especial. No pelean con los policías, tratan de evitarlos y se dejan requisar cuando lo requieren. También existen los campaneros, pagados para cumplir turnos de veinticuatro horas, ubicados en puntos clave de los tejados de las construcciones para monitorear los recorridos y tiempos de las patrullas de policía, y así avisar cuando se avecina algún operativo de allanamiento o control sobre las ollas. Estos dispositivos de vigilancia pueden ser extendidos al conjunto de los entornos descritos, a modo de economías de escala, por cuenta de los narcotraficantes o de los jíbaros para lograr un monitoreo de los movimientos de las personas que circulan o laboran allí y regular, en función de sus intereses económicos, la operación de los negocios legales e ilegales establecidos.

Los jíbaros ubicados en el centro histórico son distribuidores mayoristas que se han divido entre sí sectores ubicados por toda la ciudad, y cuidan que el negocio funcione en su entorno cercano sin eventos violentos frecuentes. Los consumidores terminales de droga que habitan en la calle, por ejemplo, deben respetar los locales comerciales alrededor de las ollas y guardar respeto mutuo al interior de las mismas. Aun así, la concentración de homicidios ha sido inevitable. Hacia Corabastos, existe la incógnita de si hay jíbaros emergentes o los expendedores dependen de los ubicados en el centro histórico. Al parecer, el dominio sobre el sector está en disputa desde que las milicias guerrilleras subversivas o los grupos paramilitares anti-insurgentes perdieron el control, al menos parcialmente; ello explicaría la concentración sobresaliente de homicidios que tienen lugar allí. Por otro lado, los habitantes de los asentamientos bajo el área de influencia de Corabastos han luchado por sus viviendas a lo largo de un proceso de regularización, y son una mano de obra disponible para las actividades informales e ilegales, de manera que el carácter de vecindario en transición permanece latente, al igual que su funcionalidad como cantera de recursos y de cubierta para los mercados ilícitos en el sector. 
Ahora bien, ¿qué ocurre en los vecindarios acomodados de la ciudad afectados por el hurto a residencias?

Excepto por Kennedy, en las localidades más afectadas por el hurto a residencias (Suba, Usaquén, Engativá y Chapinero) las condiciones de vida son más favorables a las afectadas por homicidios (gráfica 3; cuadro 2, columna D). Aunque en todas, incluida Kennedy, los vecindarios donde se concentran los hurtos pertenecen a condiciones socioeconómicas media y media-baja (estratos 4 y 3) y están integrados por edificios de apartamentos y conjuntos de casas o de apartamentos encerrados por rejas, contiguos a otros vecindarios que albergan a personas con una condición socioeconómica más baja (estrato 2); de ahí la diversidad de UPZ comprometidas en las densidades de los hurtos (gráfica 2). Estos edificios y conjuntos cerrados cuentan, por lo general, con una entrada peatonal y otra para vehículos, controladas por vigilantes contratados y cámaras de seguridad alrededor del predio. También tienen citófonos para la comunicación entre la portería y las viviendas, y entre éstas; comunicación directa con la policía; rejas internas o externas en las ventanas de las viviendas y, en fin, toda una serie de características que caricaturizan un fortín medieval o producen la sensación de arribar a una cárcel y no a un espacio de habitación.

El uso de la palabra residencia en el código penal colombiano, para identificar al objeto afectado por el hurto, refleja esa percepción de ingreso a un sitio en el que los individuos y las familias se confinan y poco interactúan entre $s^{13}$. A menos que exista el liderazgo de alguna instancia de representación comunal (consejos o juntas de administración $\left.{ }^{14}\right)$. Los residentes de un lugar que no mantienen vínculos estrechos y que, en general, no actúan en comunidad, no pueden ofrecer respuestas de grupo a desafíos colectivos, como la amenaza a su patrimonio económico. Patrimonio que se hace visible por las medidas técnicas de seguridad (rejas, porterías, cámaras) ante los transeúntes desprevenidos y los ladrones.

Las aparentes soluciones técnicas de tipo vigilantista ${ }^{15}$, más no sociales, en materia de seguridad son una medida de los miedos de unos residentes que no saben qué espacio defender. Si el vecino es un desconocido, pues la interacción con él es reducida, es difícil que inspire confianza y puede ser visto como una amenaza a la seguridad personal y patrimonial, al espacio privado de residencia. A su vez, el espacio comunal, el de interacción con los vecinos, no es desarrollado y se vuelve hostil. Por ejemplo, las cámaras de vigilancia no sólo sirven para que los porteros adviertan sobre posibles invasiones al predio del conjunto cerrado, también pueden ser usadas para observar los movimientos de los residentes en ese (supuesto) espacio comunal, de modo que todos se convierten en sospechosos potenciales de hurto o de cualquier conducta considerada impropia en los protocolos de seguridad (por ejemplo, tomar una foto desprevenida que incluya un bloque de apartamentos).

Algunos de los temas tratados en estas instancias son: manejo presupuestal, organización de eventos recreativos, condiciones de seguridad personal y patrimonial en el vecindario, entre otros.

14 El vigilantismo se inicia con la organización de la población, por cuenta propia o en colaboración con las autoridades, para detectar cualquier conducta sospechosa que amenace la seguridad de su vecindario. Pero, a la larga, fomentan desconfianza y temor entre la misma población. 
Cuando las cámaras son enfocadas hacia la calle, el espacio público se diluye. Los transeúntes son monitoreados, sin su autorización, para satisfacer un deseo (temor) de (in)seguridad de los residentes del conjunto o edificio; de quienes intentan preservar y extender su espacio que, por lo dicho hasta ahora, puede ser comunal y privado a la vez. La calle ya no es el lugar para compartir con los demás, no es vía pública, sino un escenario de competencia por residir o moverse con tranquilidad. Entonces, surge un atributo, adicional a las características de seguridad de la edificación, que hace más notable el vecindario: exclusión social.

En principio, estos inexpugnables predios demandarían el concurso de delincuentes con una elevada capacidad técnica y operativa en el hurto a residencias. Sin embargo, los ladrones han desarrollado habilidades para infiltrar espacios comunales y privados de residencia, o aprovechar la indefinición de los mismos, dado el confinamiento de las personas, convencidas de su capacidad adquisitiva y autosuficiencia para comprar servicios y equipos de vigilancia.

Las modalidades de ventosa ${ }^{16}$ o violación de cerraduras, en las que los bienes hurtados son transferidos de una residencia a otra del conjunto cerrado - antes de ser llevados a otro punto de la ciudad- muestran que en una población de extraños el nuevo no es notorio; en cambio, en una comunidad, el nuevo es un extraño. Por otro lado, la participación de empleadas del servicio doméstico y de vigilantes en las modalidades mencionadas, y en las de atraco y abuso de confianza, devela la capacidad del crimen organizado para convertir una desventaja inicial en una ventaja importante, dado que el número de vigilantes privados -alrededor de 86.000 (Acero, 2007) - excede al de efectivos de la Policía Metropolitana -alrededor de 17.000- (cuadro A2).

La tasa de ganancia de las compañías de vigilancia privada sostiene e incentiva su expansión. Esta posibilidad de extraer una renta ante una amenaza (hurto), real o ficticia, va aparejada con el tipo de residencia que se impone en Bogotá ${ }^{17}$ por cuenta de los promotores inmobiliarios, seguidores de la misma lógica de costo-beneficio. Bajo esta lógica, producen apartamentos en altura o conjuntos cerrados y no construyen un barrio de casas organizadas en manzanas hacia la calle. Inmobiliarios y familias retroalimentan una percepción de inseguridad que se concreta en la construcción de conjuntos cerrados que se convierten, entonces, en una convención urbana. Convención que mantiene la renta extraída por las empresas de vigilancia privada.

La fuente de extracción de renta para las empresas de vigilancia no se limita a la amenaza del hurto sobre la residencia. Involucra una socialización de costos hacia entes estatales, como la policía, y hacia la población, junto con una privatización de ganancias. Estas empresas no asumirán mayores costos en la preparación y mantenimiento (selección, entrenamiento, sueldos, seguridad social) de su personal para desestimular la complicidad de sus efectivos - por acción u omisión-con los delincuentes, si la policía y los funcionarios judiciales asumen toda la responsabilidad en el control del hurto a residencias. Las autoridades tienen que reaccionar

El 54,7\% de los hogares de la ciudad reside en apartamentos. 
frente a un problema que se desborda, pues su prevención queda en manos de agentes privados que no cumplen a cabalidad con sus obligaciones contractuales. De nuevo, hay una indefinición de los ámbitos públicos y privados de actuación que facilita la actividad de la delincuencia.

Para completar el cuadro, los ladrones de residencias han cualificado y profesionalizado su desempeño ${ }^{18}$. Actúan en uniones ocasionales, según la oportunidad y su evaluación de riesgos y beneficios esperados. Es decir, su desempeño es descentralizado y el líder es aquel que posea la información clave para cometer el hurto. Estas uniones coyunturales revelan que, pese a realizar tareas específicas en el hurto, los partícipes pueden adaptar sus conocimientos y destrezas a múltiples formas de coordinación delictiva, pues no están sujetos a un modus operandi distintivo de una organización. Luego, existen carreras delictivas auténticas. Para llegar a ese nivel de versatilidad en un oficio se requiere de un tiempo prolongado de aprendizaje. Entonces, no es raro encontrar capturados que han hecho sus fortunas dedicados al hurto.

Los objetos hurtados preferidos son joyas y dinero plástico (tarjetas de crédito) y en efectivo; es decir, de valor, fáciles de transportar y de ocultar. Los ladrones toman medidas de precaución, como guantes desechables de cirugía o gorros para el cabello, para no dejar huellas y no ser detectados después mediante instrumentos de última tecnología. La llamada millonaria ${ }^{19}$, las suplantaciones de funcionarios públicos y, de nuevo, la ventosa y la violación de cerraduras, son modalidades que indican una selección y seguimiento cuidadoso del objetivo; aunque, más importante, revelan un conocimiento de las víctimas en sectores pudientes de la ciudad, de sus rutinas individuales y colectivas e, incluso, de sus temores: un conocimiento del espacio urbano dónde pueden actuar y hacer presencia y que, tal vez, los moradores de Bogotá no poseemos.

\section{Conclusiones}

El crimen organizado, que ofrece o se sustenta en servicios de protección y de justicia privada, se distribuye de modo diverso por el espacio urbano bogotano, de acuerdo a tipos de vecindarios que denotan patrones de interacción social distintos entre sí. En los vecindarios periféricos de la localidad de Ciudad Bolívar ${ }^{20}$, conformados por asentamientos irregulares en sus orígenes y viviendas autoconstruidas al sur de Bogotá, ha habido mejoras en sus condiciones de habitabilidad y de accesibilidad y en equipamientos físicos, que han estimulado su crecimiento demográfico y densificación. Sin embargo, sus habitantes viven de la economía informal (del rebusque), mediante oficios de baja calificación laboral o la apertura de negocios improvisados en las primeras plantas de sus viviendas (por ejemplo,

18 Inventan el secuestro o retención policial de algún integrante de la casa para que otro integrante de la misma se convenza de entregar objetos valiosos para pagar un supuesto rescate, soborno o fianza, en un punto de la ciudad fuera de la vivienda.

19 Queda pendiente analizar otras concentraciones de homicidios en UPZ con características de vecindario periférico, al interior de las localidades de Rafael Uribe (al sur de Bogotá) y de Suba (al norte), pues Ciudad Bolívar y Kennedy fueron las jurisdicciones destacadas en la aproximación metodológica inicial.

20 Cálculos propios a partir de datos suministrados en el CICRI-MEBOG. 
venta de licor y sitios de baile), sin interés suficiente en la organización de respuestas colectivas para afrontar dificultades comunes como la delincuencia juvenil.

La participación de los jóvenes en casos de homicidio revela que quienes incurren en conductas transgresoras o punibles crecen solos, en las calles, con la ambición de emular hábitos de consumo de los sectores pudientes de la sociedad, bajo consideraciones éticas difusas y oportunidades inciertas de vida. Algunos conciben hijos a temprana edad y reproducen el déficit de atención y control parental. Así, los jóvenes quedan sujetos a la regulación violenta del crimen organizado que reprime su intervención en delitos callejeros, los coacciona para que se ocupen en mercados ilegales controlados parcialmente (tráfico de estupefacientes, protección privada financiada con extorsiones, homicidios por encargo, comercio de mercancía hurtada), y los victimiza para demostrar el potencial de control social del mismo crimen organizado.

Un segundo tipo de vecindario se presenta en el área de influencia de la Central de Abastos de Alimentos (Corabastos), ubicada en la localidad de Kennedy, al suroccidente de Bogotá. Este vecindario se encuentra a mitad de camino de un proceso de transición entre vecindario periférico, donde el uso predominante del suelo es residencial, a otro de predominio comercial. Es decir, que comporta los mismos patrones observados en los habitantes de los sectores analizados para Ciudad Bolívar mezclados con las oportunidades económicas que se han gestado en el entorno de Corabastos. Parte de las oportunidades surgen del arribo de mercados ilegales (tráfico de estupefacientes, de armas de fuego y material bélico, de mercancía hurtada) que comparten clientelas e inversiones, a semejanza de su operación en el centro histórico de la ciudad (localidades de Los Mártires y Santa Fe). En este último vecindario, funciona una plaza comercial de bienes de contrabando para consumo final e intermedio, y la sede de los distribuidores mayoristas de estupefacientes (jíbaros) de la ciudad, quienes mantienen un dispositivo de vigilancia que les permite regular las transacciones de su negocio, asegurar sus ingresos financieros y proteger y encubrir su actividad del control de las autoridades.

Los jíbaros, enfocados en el mercado urbano de base de coca, y los narcotraficantes, dedicados a la exportación de cocaína, tienen un interés común en el centro histórico y en Corabastos, pues son lugares que sirven de nodos en el tránsito de mercancías, con usos legales e ilegales, entre Bogotá y el resto del país. De ahí que el control logrado por los primeros en el centro histórico es funcional a los segundos. Sin embargo, pareciera que Corabastos carece de un jíbaro o expendedor dominante, o de una organización armada -como antes lo hicieron las milicias guerrilleras y luego los paramilitares- que regule el sector y la posibilidad de hechos violentos en vista de la concentración de homicidios y de asesinatos producto de los hurtos a personas, consumados o fallidos, en la calle. Aun así, la actividad económica, informal e ilegal, en torno a Corabastos constituye una fuente de ingresos para quienes se han asentado allí y no esperan abandonar el sector; de modo que son mano de obra disponible y cubierta para el desarrollo de tal economía. 
En vecindarios más acomodados, el crimen organizado se manifiesta mediante el hurto a residencias ubicadas en conjuntos cerrados donde habitan personas de condición socioeconómica media y media-baja (estrato 4 y 3 ), contiguos a vecindarios de condición baja (estrato 2). La complicidad de vigilantes privados y de empleadas del servicio doméstico, oficios de baja calificación laboral y la participación de jóvenes (67,0\% de los capturados, entre 2007 y 2009 , tienen entre 15 y 29 años de edad) que provienen de sectores periféricos de Bogotá, evidencian la importancia de este delito como fuente de sustento alternativo. Así, puede notarse el rol que cumple el crimen organizado como una reacción, en progreso, frente a los intentos de segregar el espacio urbano, de acuerdo a las condiciones socioeconómicas de sus habitantes, mediante medidas técnicas de protección privada que delimitan espacios vitales a modo de burbujas de seguridad.

El vigilantismo y su expresión o convención residencial urbana (conjunto cerrado) facilitan la infiltración del crimen organizado en labores de protección privada, aparejadas de una tecnología militar determinada. De esta manera, el crimen organizado puede extraer una renta (pago del servicio) de forma legal, extender sus relaciones y acopio de información hacia otros ámbitos de actividad económica (por ejmeplo, establecimientos comerciales, industriales, financieros) mediante las mismas labores de vigilancia y el concurso de personas empleadas en oficios de baja o mediana calificación, y socavar el monopolio estatal de la violencia. IEURE

\section{Referencias bibliográficas}

Acero, S. (2007). Estado actual de los servicios de vigilancia y seguridad privada que operan en Bogotá. (edición provisional). Bogotá: Secretaría Distrital de Gobierno.

Alfonso, O. (2009). Epicentrismo en mutación. Concurrencia, metropolización y cosmopolitización del centro histórico de Bogotá. Bogotá: Mimeo.

Allum, F. \& Sands, J. (2004). Explaining organized crime in Europe: are economists always right? Crime, Law and Social Change, 41, 133-160. Recuperado el 25 de marzo de 2007, de http://www. springerlink.com/content/j51q0857277273vw/fulltext.pdf

Backhaus, J. (1979). Defending organized crime? A note. The Journal of Legal Studies, 8, 3. Recuperado el 15 de enero de 2007, de http://links.jstor.org/sici ?sici=00472530\%28197906\%298\%3A3\%3C623\%3ADOCAN\%3E2.0.CO\%3B2-S.

Beltrán, I. \& Silva, G. (2006). Problemas sociológicos y de tipificación penal relacionados con el crimen organizado. En A. Martínez (Ed.). Violencia y crimen. Ensayos en memoria de Fernando Gaitán Daza. Bogotá: Universidad Externado de Colombia.

Bottoms, A. \& Wiles, P. (2002). Environmental criminology. En M. Maguire, R. Morgan y R. Reiner (Eds.). The Oxford handbook of criminology. Oxford: Oxford University Press.

Bourdieu, P. (1980). Le capital social. Actes de la recherche en sciences sociales, 31, 2-3.

Buchanan, J. (1973). A defense of organized crime? En S. Rottenberg (Ed.) Economics of crime and punishment. Amsterdam: Enterprise Institute.

Centro de Investigaciones Criminológicas (CICRI-MEBOG) (2009). Balance de delictividady desempeño institucional acumulado 2008-2009. Bogotá: Policía Metropolitana de Bogotá. Mimeo. 
Cohen, L. \& Felson, M. (1979). Social change and crime rate trends: a routine activities approach. American sociological review, 44, 508-608.

DANE. (2010). Medición del empleo informal. Trimestre móvil octubre-diciembre 2009. Boletín de prensa. Bogotá. Recuperado el 27 de febrero de 2010, de http://www.dane.gov.co/files/ investigaciones/boletines/ech/ech_informalidad/bolet_ech_informalidad_oct_dic2009.pdf

Dick, A. (1995). When does organized crime pay? A transaction cost analysis. International Review of Law and Economics, 15, 25-45.

Finckenauer, J. (2005). Problems of definition: what is organized crime? Trends in Organized Crime, 8, 3, 63-83. Recuperado el 11 de enero de 2007, de http://www.springerlink.com/content/ mkft2tyucqm0a82c/fulltext.pdf

Fiorentini, G. (2000). Organized crime and illegal markets. En B. Bouckaert y G. De Geest (Eds.) Encyclopedia of law and economics, volume $V$, The economics of crime and litigation. Cheltenham: Edward Elgar. Recuperado el 15 de enero de 2007, de http://encyclo.findlaw. com/8400book.pdf.

Gaitán, F. (2006). El crimen organizado en Colombia. Una breve revisión. En A. Martínez (Ed.). Violencia y crimen. Ensayos en memoria de Fernando Gaitán Daza. Bogotá: Universidad Externado de Colombia.

Gaviria, A. (1998). Increasing returns and the evolution of violent crime: the case of Colombia. Discussion Paper, No. 98-14, 1-41. San Diego: University of California. Recuperado el 3 de octubre de 2007, de http://repositories.cdlib.org/cgi/viewcontent.cgi ?article=1225\&context=ucsdecon

Hagan, F. (2006). "Organized Crime” and "organized crime”: indeterminate problems of definition. Trends in Organized Crime, 9, 4, 127-137. Recuperado el 11 de enero de 2007, de http://www. springerlink.com/content/8aneflca71jwe2ja/fulltext.pdf

Hataya, N. (2009). La ilusión de la participación comunitaria. Lucha y negociación en los barrios irregulares de Bogotá 1992-2003. Bogotá: Universidad Externado de Colombia. En imprenta.

Kempa, M. et al. (1999). Reflections on the evolving concept of private policing. European Journal on Criminal Policy and Research, 7, 197-223. Recuperado el 7 de abril de 2007, de http://www. springerlink.com/content/p23r814k637110u5/fulltext.pdf

Putnam, R. (1993). Making democracy work. Civic traditions in modern Italy. Princeton: Princeton University Press.

Rocke, P. (2002). Sociological theories of crime, En M. Maguire, R. Morgan, y R. Reiner (Eds.). The Oxford handbook of criminology. Oxford: Oxford University Press, 51-82.

Rose-Ackerman, S. (1985). Inalienability and the theory of property rights. Columbia Law Review, 85, 931-969.

Sampson, R.; Raudenbush, S. \& Earls, E. (1997). Neighborhoods and violent crime: a multi-level study of collective efficacy. Science, 277, 918-924.

Schelling, T. (1971). What is the business of organized crime? Journal of Public Law, 20, 71-84.

Shaw, C. \& McKay, H. (1942). Juvenile delinquency and urban areas (III). Chicago: University of Chicago Press.

Siisiäinen, M. (2000). Two concepts of social capital: Bourdieu vs. Putnam. Documento presentado a la cuarta conferencia internacional ISTR: The Third Sector: for What and for Whom? Dublin: Trinity College. Recuperado el 6 de abril de 2007, de http://www.istr.org/conferences/dublin/ workingpapers/siisiainen.pdf. 
Silva, G. (2006). De la desviación a la divergencia: introducción a la teoría sociológica del delito. En A. Martínez (Ed.) Violencia y crimen. Ensayos en memoria de Fernando Gaitán Daza. Bogotá: Universidad Externado de Colombia.

Velásquez, C. (2010). Sicariato en Bogotá: emergencia y desarrollo de una modalidad homicida en la ciudad. Una aproximación cualitativa y exploratoria. Forensis 2009. Datos para la vida. Bogotá: Instituto Nacional de Medicina Legal y Ciencias Forenses. En imprenta. 


\section{Anexo 1}

CUADRO A1 | Distribución porcentual de los móviles de homicidios comunes en Bogotá (años 2007-2009)

\begin{tabular}{|c|c|c|c|c|c|c|c|}
\hline LOCALIDAD & $\begin{array}{l}\text { Problemas } \\
\text { PERSONALES } \\
\text { (A) }\end{array}$ & $\begin{array}{c}\text { Problemas } \\
\text { Pasionales } \\
\text { (B) }\end{array}$ & $\begin{array}{c}\text { Problemas } \\
\text { FAmiliares } \\
\text { (C) }\end{array}$ & $\begin{array}{c}\text { Venganza } \\
\text { (D) }\end{array}$ & $\begin{array}{c}\text { AJUSTE DE } \\
\text { CUENTAS } \\
\text { (E) }\end{array}$ & $\begin{array}{c}\text { POR } \\
\text { HURTARLE } \\
(\mathrm{F})\end{array}$ & $\begin{array}{c}\text { POR } \\
\text { HURTAR } \\
(G)\end{array}$ \\
\hline USAQUÉN & 3,1 & 2,5 & 5,4 & 5,6 & 5,9 & 3,8 & 3,5 \\
\hline Chapinero & 1,0 & 1,3 & 0,0 & 1,3 & 0,7 & 2,3 & 1,2 \\
\hline SANTA FE & 5,9 & 5,7 & 3,6 & 4,6 & 4,0 & 5,2 & 4,7 \\
\hline SAN CRISTÓbAL & 8,0 & 3,8 & 3,6 & 4,6 & 6,3 & 4,3 & 3,5 \\
\hline Usme & 7,2 & 5,7 & 5,4 & 4,7 & 5,4 & 6,4 & 1,2 \\
\hline Tunjuelito & 2,4 & 2,5 & 7,1 & 2,1 & 2,0 & 2,3 & 2,4 \\
\hline Bosa & 5,9 & 8,2 & 7,1 & 5,9 & 5,7 & 6,1 & 3,5 \\
\hline KENNEDY & 14,4 & 11,3 & 12,5 & 14,7 & 14,9 & 20,9 & 25,9 \\
\hline FonTiBón & 1,8 & 4,4 & 5,4 & 2,7 & 2,6 & 2,9 & 3,5 \\
\hline Engativá & 6,4 & 11,3 & 12,5 & 6,7 & 6,9 & 7,2 & 7,1 \\
\hline Suba & 8,4 & 11,3 & 5,4 & 9,1 & 7,3 & 7,2 & 4,7 \\
\hline BARRIOS UNIDOS & 1,0 & 3,1 & 0,0 & 3,1 & 2,6 & 2,6 & 1,2 \\
\hline Teusaquillo & 0,8 & 1,3 & 0,0 & 1,7 & 1,6 & 2,0 & 3,5 \\
\hline Los MÁrtires & 6,2 & 0,6 & 0,0 & 5,1 & 5,7 & 2,6 & 7,1 \\
\hline ANTONIO NARIÑo & 2,1 & 1,3 & 1,8 & 1,5 & 1,0 & 0,9 & 2,4 \\
\hline Puente Aranda & 1,8 & 3,8 & 0,0 & 2,4 & 4,3 & 3,8 & 3,5 \\
\hline La CANDElaria & 0,9 & 0,0 & 0,0 & 0,5 & 0,1 & 0,3 & 0,0 \\
\hline RAFAEL URIBE URIBE & 7,2 & 9,4 & 12,5 & 6,9 & 6,4 & 6,4 & 5,9 \\
\hline CIUdad Bolívar & 15,5 & 12,6 & 17,9 & 16,7 & 16,7 & 12,8 & 15,3 \\
\hline TOTAL Bogotá & 100,0 & 100,0 & 100,0 & 100,0 & 100,0 & 100,0 & 100,0 \\
\hline
\end{tabular}

FUENTE ELABORACIÓN PROPIA. DATOS SUMINISTRADOS EN EL CICRI-MEBOG, SUJETOS A VARIACIÓN. 
Anexo 2

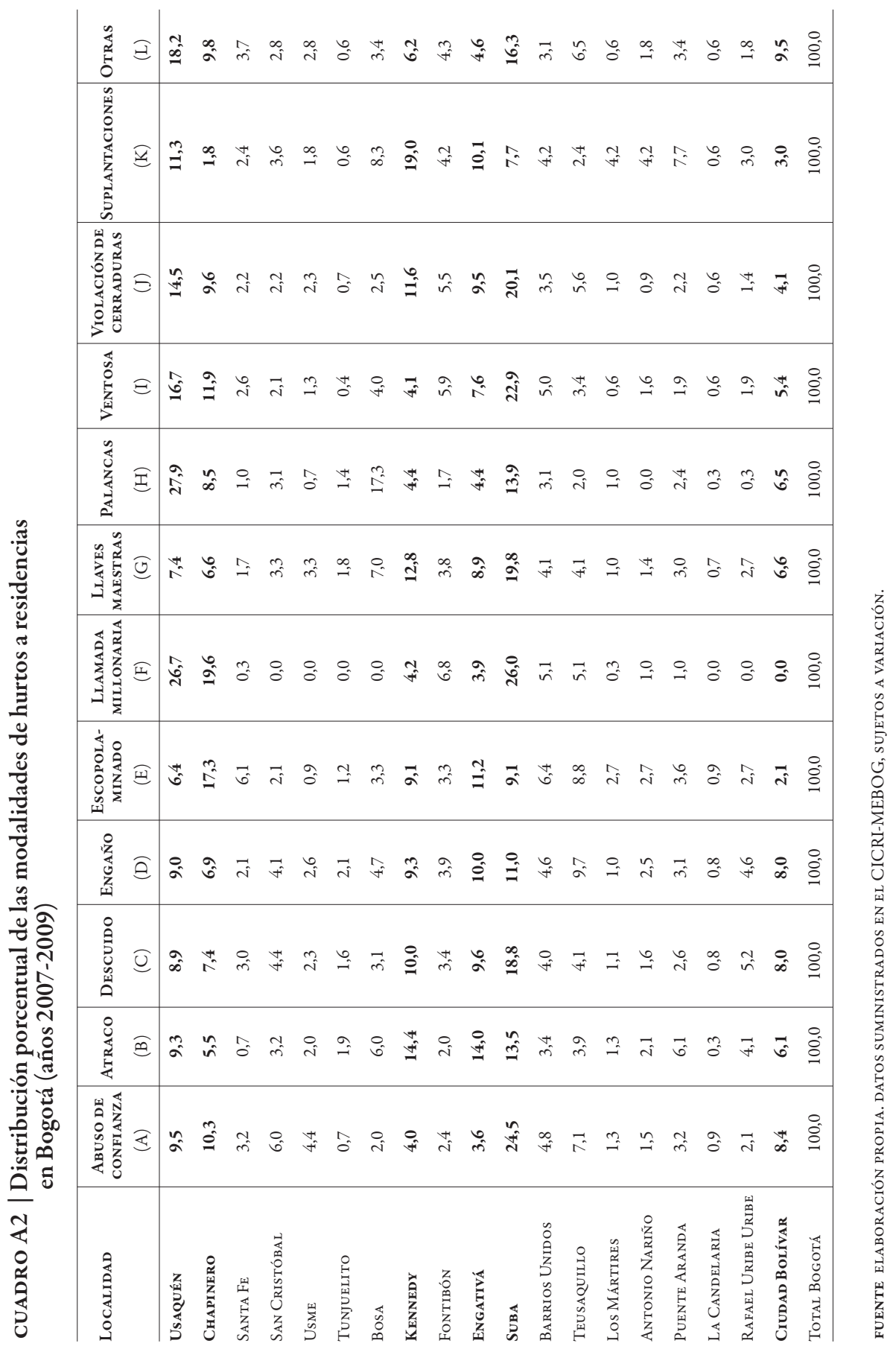

